\title{
Implementation of an electronic nose for classification of synthetic flavors
}

\author{
Radi, Barokah, Dwi Noor Rohmah, Eka Wahyudi, Muhammad Danu Adhityamurti, Joko Purwo \\ Leksono Yuroto Putro \\ Department of Agricultural and Biosystems Engineering, Faculty of Agricultural Technology, Universitas Gadjah Mada, \\ Yogyakarta, Indonesia
}

\begin{tabular}{l} 
Article Info \\
\hline Article history: \\
Received Aug 30, 2020 \\
Revised Nov 3, 2020 \\
Accepted Apr 20, 2021 \\
\hline
\end{tabular}

Keywords:

Aroma pattern

Classification

Electronic nose

Principal component analysis

Synthetic flavor

\begin{abstract}
Classification and identification of synthetic flavor become routine activities in the flavor and food industry due to its application. As a modern olfactory technology, electronic nose (e-nose) has the possibility to be applied in these activities. This study aimed to evaluate an e-nose for classifying synthetic flavors. In this study, an e-nose was designed with an array of gases sensors as the main sensing component and principal component analysis (PCA) for the pattern recognition software. This research was started with preparation of the hardware, continued with preparation of sample, data collection, and analysis. There were nine samples of synthetic flavors with different aroma, namely: grapes, strawberry, mocha, pandanus, mango, jackfruit, orange, melon, and durian. The data collection process includes three stages, i.e. flushing, collecting, and purging of $2 \mathrm{~min}, 3 \mathrm{~min}, 2 \mathrm{~min}$ respectively. These sensor responses were then analyzed for forming aroma patterns. Four pretreatment methods were applied for the aroma pattern formation: absolute data, normalize of absolute data, relative data, and normalize of relative data. With the PCA for evaluation, the results showed that the absolute data treatment provided the best results, indicated from the distribution of aroma patterns that were grouped according to the type of samples.
\end{abstract}

This is an open access article under the CC BY-SA license.

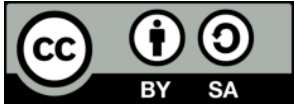

\section{Corresponding Author:}

Radi

Department of Agricultural and Biosystems Engineering

Faculty of Agricultural Technology

Universitas Gadjah Mada

Jl. Flora no. 1, Bulaksumur, Yogyakarta 55281, Indonesia

Email: radi-tep@ugm.ac.id

\section{INTRODUCTION}

In the food processing, a number of flavors can be formed or can be degraded [1]. On the one hand, flavor is the main quality attribute that determines the level of acceptance of a food product by consumers. Therefore, the existence of flavors in accordance with consumer tastes is very important so that a food product can be accepted. Flavor is the sensation that consumers feel when they consume food [1]. It comes from the interaction between taste, aroma, and texture. Of course, to get a strong flavor, taste and aroma components must be available in food products. Often, these components are available in small quantities that are below human detection capability and can be lost during processing or storage. Thus, the flavor of food products may not occur or do not give a strong flavor. For this reason, several food industries add a number of components of taste and aroma, called flavoring compounds, to create acceptable flavor for their food products. 
Flavor is a food additive that affects the taste and aroma of food or beverages [2]. For aromatization, food industries usually use aroma concentrates, essences, extracts and individual compounds [1]. Based on the ingredients, flavors are divided into 2 types, namely natural flavors and synthetic flavors [3]. Food industries may prefer synthetic flavors over natural flavors because they are easy to be obtained and used [4]. So that synthetic flavor producers continue to innovate according to market demand. In terms of maintaining the quality of their product, flavor producers should carry out sensory tests. One of the most important sensory tests to do in the industry is testing of the smell. The sensory tests are also conducted regularly in food industries. Since the aroma becomes the most important quality attributes for food acceptability, the testing should be conducted regularly. Usually, industries conduct the sensory testing by applying a group of panelists [5]. However, it is not always possible for a panelist to perform consistent analysis, either due to the panelist's health condition or the panelist's capacity to manually analyze the aroma of a material. Therefore, an analytical instrument that has a function like the human olfactory organ is necessary. For both industries, food and synthetic flavor, the tool is specifically expected to be a quality control instrument. One of the important devices which is able to identify and classify smell is called an electronic nose (e-nose).

Electronic nose (e-nose) is an instrument designed to imitate the working principles of the biological olfactory system of humans or animals. The e-nose is an instrument that combines a series of gas sensors and pattern processing techniques for detecting scents [6]. E-nose is also called olfactory electronics because it has the ability to mimic the way the human sense of smell works [7]. E-nose is needed in various processes, especially which require the role of sense of smell, including in the food and flavor industry. Several studies on electronic nose in detecting and classifying aroma that have been carried out are organic green teas [8], black tea classification [9] [10], herbal tea beverage discrimination [11], yogurt flavor assessment [12], analysis of ethanol in soy sauce [13], determination of trimethylamine in milk [14], honey nectar detection [15], and meat and fish assessment [16]. Referring to the previous research, in this work, the e-nose will be implemented to classify synthetic flavors. The focus of this test is to find out whether the electronic nose can classify several synthetic flavors using the principal component analysis (PCA) method [11], [14], [17]-[20].

\section{RESEARCH METHOD}

\subsection{Sample}

The sample used in this research are synthetic flavors produced by the same industry (same brand) which have different aromas. There were nine different aromas of flavor: grape, melon, jackfruit, pandanus, strawberry, durian, orange, mango, and mocha. Each sample of synthetic flavors was prepared as much as 5 $\mathrm{ml}$ using a measuring cup. The sample is then put into the prepared cup and then placed inside the sample cup. The sample should remain inside the cup at least 1 minute before data collection begins.

\subsection{Hardware}

The hardware used in this study consisted of an e-nose, sample cup, carrier gas, and a computer. The e-nose used in this research was designed with four main parts, namely as a sample handling system, a series of gas sensors with suitable conditioning circuit as detector, an interface and controller for data acquisition, and computer for data collection and analysis. The part of sample handling was designed by combination of two pieces of three-way solenoid valve, sample cup, and carrier gas. The detector consisted of 13 MOS sensors. The use of MOS sensors which have a sensitivity to certain gas compounds for detecting part of an e-nose was also reported in [15], [17]-[18]. A signal conditioning circuit with a voltage divider was also applied in the e-nose. As also applied in [7], the e-nose also completed with a temperature-humidity sensor (DHT22). A microcontroller of Arduino Mega was applied for analog to digital converter (ADC), interface, and controller. The e-nose was developed in the Laboratory of Agricultural Energy \& Machinery, Faculty of Agricultural Technology, Universitas Gadjah Mada. The e-nose system aims to obtain efficient gas sensor response so that the flow of sample and carrier gases are regulated. The working principle of the e-nose can be seen in Figure 1, which starts from the pressurized gas entering valve 1 then flows to valve 2 which can go through part 1 or part 2 , then flows to valve 2, temperature and humidity sensors, gas sensors, and finally will be forwarded to the computer.

\subsection{Software}

The e-nose circuit controlled by the microcontroller is communicated to the computer via a universal serial bus (USB) line. To operate the e-nose, it is completed with a graphical user interface (GUI). Some menus available on the GUI include start, stop, save, reset, close button. The GUI functions as a display program and hardware controller in measuring samples, the data displayed is the response of the gas sensor, the response of the temperature and humidity sensors. Sample measurement consisted of one sniffing cycle, namely flushing, collecting, and purging as shown in Figure 2, this process has also been cried out in 
[21], [22]. Flushing is the process of reading the sensor response without a test sample. The result of this process is a reference value for sensor readings when exposed to clean air. The flushing part is done for 2 minutes. Collecting is the process of flowing the sample aroma into the sensor room so that the sensor response is exposed to the smell of the test sample, this process lasts 3 minutes. Purging is the process of recleaning the sensor chamber from the smell of the previous sample. This process lasts for 2 minutes. The result of this process is a decrease in the signal caused by the smell of the sample flowing into the sample chamber being cut off or closed by a valve.



(a)

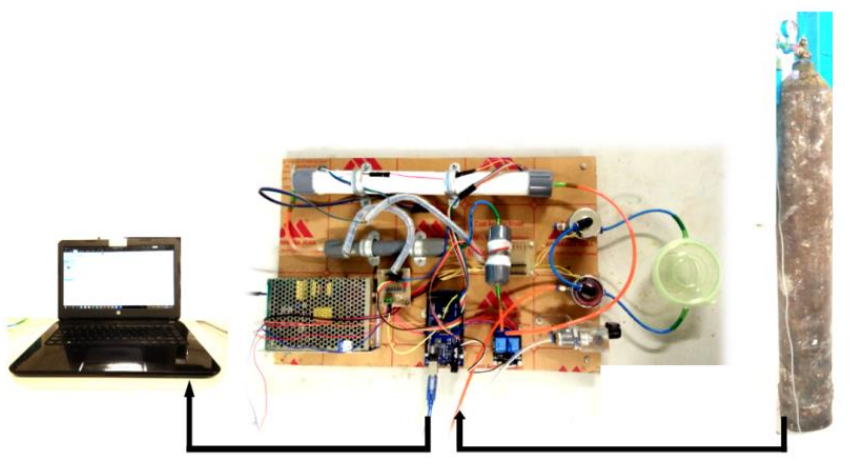

(b)

Figure 1. Experimental setup of e-nose system, (a) Schematic design, (b) Real hardware

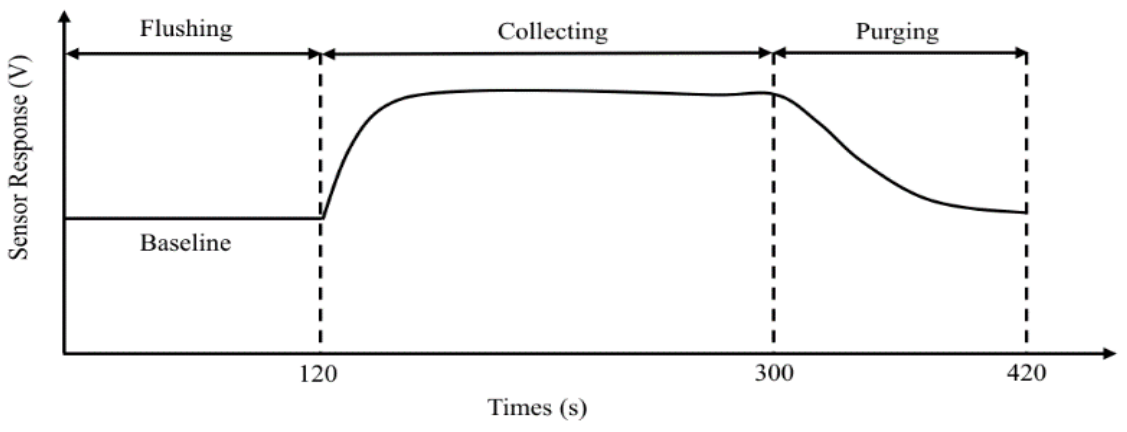

Figure 2. Process of sampling

\subsection{Analysis procedure}

The sensor response data from the sample exposure is converted to voltage using signal conditioners [1]. Furthermore, the data will be displayed on the computer in the form of an excel file. The data will be analyzed so that the pattern results of each synthetic flavor are obtained. The data analysis steps are explained as follow: 


\subsubsection{Pre-treatment data processing}

The data that has been stored in the form of an excel file is pre-treated with data processing which consists of 4 management methods, namely (a) the absolute data method, (b) normalize absolute data, (c) relative data, and (d) normalize relative data. Normalization baseline data have also been carried out by Liu et al. [23]. Prior to pre-treatment, it must be preceded by determining the constant range of data from the flushing and collecting processes. Absolute data is constant data obtained from the collecting process, normalize absolute data is constant data divided by the maximum value of the data, relative data is constant data from the collecting process minus constant data from the flushing process, and normalize relative data is the relative value of data divided by the maximum value of the data. The maximum value that is processed using the normalize method is 1 . The purpose of this pretreatment process is to obtain the difference in pattern recognition between synthetic flavor samples.

\subsubsection{Principal component analysis}

Principal component analysis (PCA) is a method of data transformation with many variables that may interact with each other into new data with the same number of variables, but the new variables are not correlated. In this research, PCA based on covariance matrix is applied. This method was also applied in [7], includes a series step. The analysis is started by calculating the covariance matrix from the aroma patterns of samples, extracting the eigenvalue and eigenvector, then transforming the original data into the new data by using selected eigenvector. Each new data variable contains a number of variances which are important information from the data. This new variable is commonly called principal component (PC). In PCA, each $\mathrm{PC}$ is sorted based on the amount of the carried information, where PC-1 contains the largest variant, followed by PC-2, then PC-3, and so on to PC-n. Generally, the use of some early PCs has brought most of the information from the processed data so that it is possible to be visualized. The data obtained from the pretreatment of data processing then analyzed using the PCA program. The results obtained from processing using the PCA method are graphs showing the relationship between the first component (x-axis) or called PC-1 and the second component (y-axis) or called PC-2. The PCA analysis graph will show the plot score of nine samples. Each point on the PCA analysis graph represents one replication per sample so that 1 test sample will produce 30 points (data) according to the test data replication.

\section{RESULTS AND DISCUSSION}

\subsection{Gas sensor response}

Data collection begins with sample preparation. The sample that has been prepared with the same volume is then put in a closed sample container. E-nose is prepared for at least 2 minutes before use. By pressing the start button on the GUI, the data retrieval process starts. The data collection process for each sample was carried out for 7 minutes, which included flushing for $2 \mathrm{~min}$, collecting for 3 min, and purging for $2 \mathrm{~min}$. Data reading was carried out with a period of a second, so that in each sample there were 420 data from each sensor used. The data is represented in the form of voltage values. In this design, the e-nose contains 13 MOS sensors. Data of the sensor response to the presented sample is displayed in the GUI. Testing of e-nose without samples with the same method is carried out to determine the comparison of sensor responses before and after being presented the sample. The sensor response with the presentation of the sample can be seen in Figure 3.

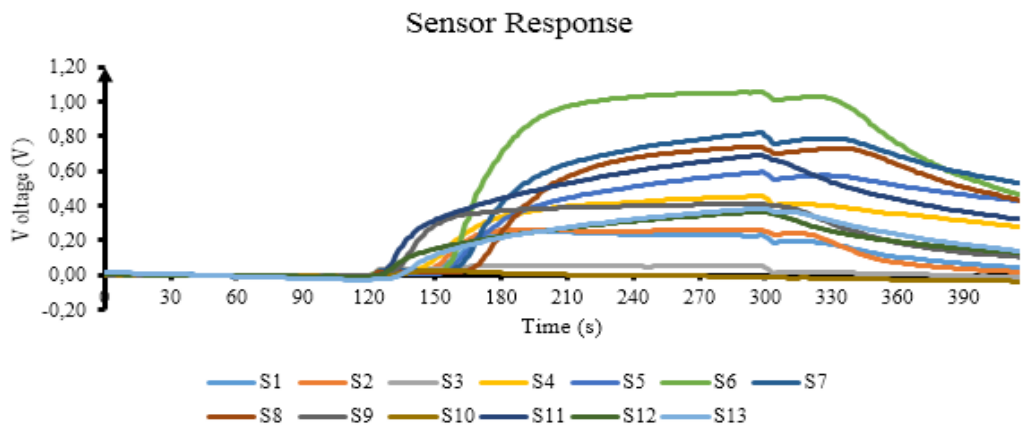

Figure 3. Response of gas sensor with the presentation of sample

In addition to the gas sensor array, the e-nose circuit used is also equipped with a temperature and relative humidity $(\mathrm{RH})$ sensor. The temperature and $\mathrm{RH}$ data readings by the sensor are also displayed in the GUI. Sample of it can be seen in Figure 4. The change in humidity response in the collecting process shows 
that the sample being presented may contain water. D. Lelono, K. Triyana, S. Hartati, and J. Istiyanto [24] the greater the sample room temperature in the data collection process, the greater the intensity of the sensor response. The temperature sensor response is consistent enough during the data collection process so that the temperature does not significantly affect the change in gas response.



Figure 4. Temperature and humidity of sample during sampling

\subsection{Results of principal component analysis}

In this study, PCA was used to map the aroma pattern data of all analyzed samples. This study analyzed nine samples of synthetic flavor available in the market. These include grape, melon, jackfruit, pandanus, strawberry, durian, orange, mango, and mocha flavors. By using the covariance matrix base, PCA generates a new data matrix which is transformed from the eigenvector values obtained. In this analysis, two PCs are used so that new data can be visualized in 2-dimensional graphical form. By applying PC-1 on the xaxis and PC-2 on the y-axis, aroma pattern data from the PCA results can be displayed. Figure 5 presents the distribution of aroma patterns obtained by the four pretreatment methods used: (a) absolute data, (b) normalized absolute data, (c) relative data, (d) normalized relative data.

Based on the distribution of the aroma patterns of the analyzed samples, it can be seen that Figure 5(a) shows the best results and shows the distribution of clustered aroma patterns for data from the same sample and each sample tends to separate from one another. Based on this graph, this analysis shows that there are at least seven samples from nine samples that can be grouped. While the PCA for aroma pattern data analyzed with pretreatment absolute data were normalized as shown in Figure 5(b), the aroma patterns for each sample tended to blend with one another, making it difficult to identify. Meanwhile, the results of data analysis with pretreatment were relatively poor in terms of pattern grouping. The results of this analysis only show a few classifiable patterns (about three types of synthetic flavors). Likewise, for the analysis of the aroma pattern data formed by the pretreatment method of the normalized relative data. The analysis results show the distribution of aroma patterns that cannot be grouped. Based on these results, the pretreatment of absolute data method can be selected for the purpose of classification or identification of synthetic flavors by using an e-nose combined with PCA.

Figure 5(a) shows that the samples are grouped and easily separated. Although there were some sample points that were mixed with other samples, most of the samples were able to be classified. Based on this graph, the distribution of aroma patterns presented in Figure 5(a) has presented 84\% of the information from the data $(60.9 \%$ from PC-1 and $23.1 \%$ from PC-2). The information value of $84 \%$ can certainly represent research data. Of course, the value of the information represented by this new data can be increased by adding another PC, for example PC-3. The addition of PC-3 can increase the amount of variance information of the initial data generated, which is possible to produce a better grouping of data. However, the use of 3 PCs in this analysis has not been carried out. Forward analysis with 3 PCs is possible to follow up this study.

The results of the distribution of aroma patterns presented in Figure 5(a) show that there are a number of points that are close to each other even though these points come from different types of samples. The overlapping score plots may be caused by the similar content of compounds in the sample. An example is between the melon and strawberry flavor samples. I. Gonda et al. [25], melons and strawberries contain the same ester compounds, namely methyl acetate and ethyl acetate. This is also reinforced from other references, melons and strawberries have the same synthetic ester, namely ethyl 2 methylbutyrate. Other test samples that have overlapping points are strawberry and jackfruit flavor. B. T. Ong et al. [26], both samples have the same ester content, namely butyl acetate. Thus, most likely the cause of point crush between 
samples is because the test sample contains the same ester compound. The results of PCA analysis on nine samples showed that the electronic nose was able to distinguish the synthetic taste that was seen from several samples that could be grouped well [27].



(a)



(c)



(b)

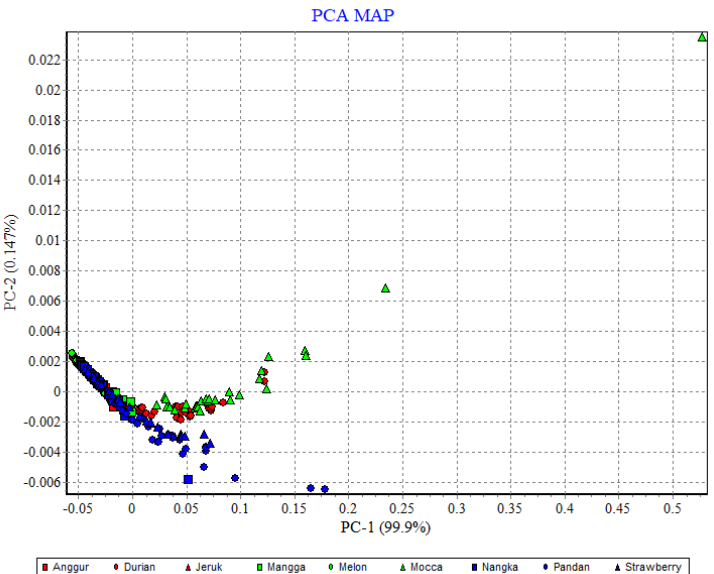

(d)

Figure 5. Score plot of PCA with four different pretreatments, (a) Absolute data, (b) Normalized absolute data, (c) Relative data, (d) Normalized relative data

\section{CONCLUSION}

Study on the implementation of e-nose based on a gas sensor array for classification of synthetic flavors has been conducted. These MOS sensors provide a good response to the sample presentation indicated from the difference between sensor response and the baseline. Classification analysis using the PCA method, pre-treatment with absolute data analysis resulted in the best results. Based on PCA, by using two main components (PC-1 and PC-2), the distribution of aroma patterns formed by this treatment showed that at least seven samples can be calcified properly. The synthetic flavors classified well were the flavors for grape, melon, pandanus, strawberry, orange, mango, and mocha, while the samples of jackfruit and durian flavors tended to mix with other samples. From the result, the aroma pattern of strawberry and jackfruit tended to be mixed.

\section{ACKNOWLEDGEMENTS}

We would like to thank to Universitas Gadjah Mada (RTA Grant) for funding this research. We are also grateful for all the support from members of Agricultural Energy and Machinery for supporting this research. 


\section{REFERENCES}

[1] H.-D. Belitz, W. Grosch, and P. Schieberle, "Food Chemistry," 4th ed. Berlin Heidelberg: Springer-Verlag, 2009.

[2] G. Astray, L. García-Río, J. Mejuto, and L. Pastrana, "Chemistry in food: Flavours," Electron. J. Environ. Agric. Food Chem., vol. 6, pp. 1742-1763, Feb. 2007.

[3] K. Poornima and R. Preetha, "Biosynthesis of Food Flavours and Fragrances - A Review," Asian J. Chem., vol. 29, pp. 2345-2352, Jan. 2017, doi: 10.14233/ajchem.2017.20748.

[4] M. Baietto and A. D. Wilson, "Electronic-Nose Applications for Fruit Identification, Ripeness and Quality Grading," Sensors, vol. 15, no. 1, Art. no. 1, Jan. 2015, doi: 10.3390/s150100899.

[5] G. ZHU and G. YU, "A pineapple flavor imitation by the note method," Ciênc. E Tecnol. Aliment., vol. 40, Dec. 2020, doi: 10.1590/fst.26019.

[6] H. Harianto, M. Rivai, and D. Purwanto, "Implementation of Electronic Nose in Omni-directional Robot," International Journal of Electrical and Computer Engineering (IJECE), vol. 3, no. 3, no. 3, pp. 399-406, June 2013, doi: 10.11591/ijece.v3i3.2531.

[7] Radi, M. Rivai, and M. H. Purnomo, "Study on Electronic-Nose-Based Quality Monitoring System for Coffee Under Roasting," J. Circuits Syst. Comput., vol. 25, no. 10, Art. no. 10, May 2016, doi: 10.1142/S0218126616501164.

[8] H. Liu, D. Yu, and Y. Gu, "Classification and Evaluation of Quality Grades of Organic Green Teas Using an Electronic Nose Based on Machine Learning Algorithms," IEEE Access, vol. 7, pp. 172965-172973, 2019, doi: 10.1109/ACCESS.2019.2957112.

[9] D. Lelono, K. Triyana, S. Hartati, and J. Istiyanto, "Classification of Indonesia black teas based on quality by using electronic nose and principal component analysis,” Jul. 2016, vol. 1755, p. 020003, doi: 10.1063/1.4958468.

[10] B. Tudu et al., "Towards Versatile Electronic Nose Pattern Classifier for Black Tea Quality Evaluation: An Incremental Fuzzy Approach," IEEE Trans. Instrum. Meas., vol. 58, no. 9, pp. 3069-3078, Sep. 2009, doi: 10.1109/TIM.2009.2016874.

[11] J. Jin, S. Deng, X. Ying, X. Ye, T. Lu, and G. Hui, "Study of herbal tea beverage discrimination method using electronic nose," J. Food Meas. Charact., vol. 9, no. 1, pp. 52-60, Mar. 2015, doi: 10.1007/s11694-014-9209-0.

[12] H. Tian et al., "Correction to: Combined application of electronic nose analysis and back-propagation neural network and random forest models for assessing yogurt flavor acceptability," J. Food Meas. Charact., vol. 14, Aug. 2020, doi: 10.1007/s11694-020-00467-4.

[13] S. Park, S. Lee, Y. Sim, J. Choi, E. Park, and B. Noh, "Analysis of ethanol in soy sauce using electronic nose for halal food certification," Food Sci. Biotechnol., vol. 26, pp. 311-317, Apr. 2017, doi: 10.1007/s10068-017-0042-1.

[14] S. Ampuero, Z. Thierry, V. Gustafsson, A. Lundén, and J. Bosset, "Determination of trimethylamine in milk using an MS based electronic Nose," Eur. Food Res. Technol., vol. 214, pp. 163-167, Feb. 2002, doi: 10.1007/s00217001-0463-0.

[15] N. Liu, B. Shi, L. Zhao, Z. Qing, B. Ji, and F. Zhou, "Research on Pattern Recognition Method for Honey Nectar Detection by Electronic Nose," Dec. 2015, pp. 393-403, doi: 10.1007/978-3-319-19620-6 44.

[16] S. Grassi, S. Benedetti, M. Opizzio, E. di Nardo, and S. Buratti, "Meat and Fish Freshness Assessment by a Portable and Simplified Electronic Nose System (Mastersense)," Sensors, vol. 19, no. 14, Art. no. 14, Jan. 2019, doi: 10.3390/s19143225.

[17] S. Lihuan, W. Liu, Z. Xiaohong, H. Guohua, and Z. Zhidong, "Fabrication of electronic nose system and exploration on its applications in mango fruit (M. indica cv. Datainong) quality rapid determination," J. Food Meas. Charact., vol. 11, Dec. 2017, doi: 10.1007/s11694-017-9579-1.

[18] S. Borah, E. Hines, M. Leeson, D. Iliescu, M. Bhuyan, and J. W. Gardner, "Neural network based electronic nose for classification of tea aroma," Sens. Instrum. Food Qual. Saf., vol. 2, pp. 7-14, Mar. 2008, doi: 10.1007/s11694007-9028-7.

[19] H. J. Han, S. H. Lee, J. Y. Moon, S. Park, H. Dong, and B. S. Noh, "Discrimination of the cultivar, growing region, and geographical origin of rice (Oryza sativa) using a mass spectrometer-based electronic nose," Food Sci. Biotechnol., vol. 25, no. 3, pp. 695-700, 2016, doi: 10.1007/s10068-016-0121-8.

[20] H. Guohua, W. Yuling, Y. Dandan, and D. Wenwen, "Fuji Apple Storage Time Predictive Method Using Electronic Nose," Food Anal. Methods, vol. 6, no. 1, pp. 82-88, Feb. 2013, doi: 10.1007/s12161-012-9414-6.

[21] D. Lelono, M. Z. Abdillah, T. W. Widodo, and M. Apandi, "Clusterization of Pure And Formalin Fresh Noodles with Electronic Nose Based on Kernel Principal Component Analysis," in 2019 5th International Conference on Science and Technology (ICST), Jul. 2019, vol. 1, pp. 1-5, doi: 10.1109/ICST47872.2019.9166268.

[22] D. Lelono, H. Nuradi, M. R. Satriyo, T. W. Widodo, A. Dharmawan, and J. E. Istiyanto, "Comparison of Difference, Relative and Fractional Methods for Classification of The Black Tea Based on Electronic Nose," in 2019 International Conference on Computer Engineering, Network, and Intelligent Multimedia (CENIM), Nov. 2019, pp. 1-7, doi: 10.1109/CENIM48368.2019.8973308

[23] L. Liu, X. Li, Z. Li, and Y. Shi, "Application of Electronic Nose in Detection of Fresh Vegetables Freezing Time Considering Odor Identification Technology," Chem. Eng. Trans., vol. 68, pp. 265-270, Oct. 2018, doi: 10.3303/CET1868045.

[24] D. Lelono, K. Triyana, S. Hartati, and J. Istiyanto, "Development of Electronic Nose with High Stable Sample Heater to Classify Quality Levels of Local Black Tea," Int. J. Adv. Sci. Eng. Inf. Technol., vol. 7, p. 352, Apr. 2017, doi: 10.18517/ijaseit.7.2.1659.

[25] I. Gonda et al., "Biosynthesis and perception of melon aroma," in Biotechnology in Flavor Production, Second Edition, 2016, ch. 11, pp. 281-305. 
[26] B. T. Ong et al., "Analysis of volatile compounds in five jackfruit (Artocarpus heterophyllus L.) cultivars using solid-phase microextraction (SPME) and gas chromatography-time-of-flight mass spectrometry (GC-TOFMS)," $J$. Food Compos. Anal., vol. 21, no. 5, pp. 416-422, Aug. 2008, doi: 10.1016/j.jfca.2008.03.002.

[27] D. Lelono, D. Permana, F. Achmad, T. W. Widodo, M. A. Bramantya, and K. Triyana, "Quality Classification of Chili Sauce Using Electronic Nose with Principal Component Analysis," in 2018 4th International Conference on Science and Technology (ICST), Aug. 2018, pp. 1-5, doi: 10.1109/ICSTC.2018.8528292.

\section{BIOGRAPHIES OF AUTHORS}
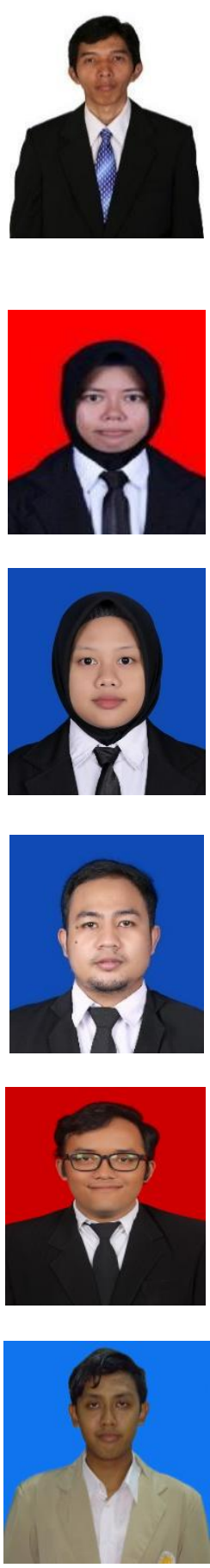

Dr. Radi, STP., M.Eng. is a lecturer at the Department of Agricultural and Biosystems Engineering, Faculty of Agricultural Technology, Universitas Gadjah Mada, Indonesia. He received his bachelor's degree from that department, master's degree from Department of Electrical Engineering, Faculty of Engineering, Universitas Gadjah Mada, doctoral degree from Department of Electrical Engineering, Faculty of Industrial Technology, Institut Teknologi Sepuluh Nopember, Indonesia. Currently, he is head of the Agricultural Energy \& Machinery Laboratory. His research interest is associated with the research group of agricultural control \& robotics which covers electronic nose, machine vision, bio-sensing, biosystems control \& robotics.

Barokah is a master's student of the Department of Agricultural and Biosystems Engineering, Faculty of Agricultural Technology, Universitas Gadjah Mada, Indonesia, Indonesia. Currently, she is a member of the research group of agricultural control \& robotics. Her research interest is application of an electronic nose for food quality.

Dwi Noor Rohmah is bachelor's student of Department of Agricultural and Biosystems Engineering, Faculty of Agricultural Technology, Universitas Gadjah Mada, Indonesia, Indonesia. Currently, she is a member of the research group of agricultural control \& robotics. Her research interest is application of an electronic nose for food quality assessment.

Eka Wahyudi is bachelor's student of Department of Agricultural and Biosystems Engineering, Faculty of Agricultural Technology, Universitas Gadjah Mada, Indonesia, Indonesia. Currently, he is a member of the research group of agricultural control \& robotics. His research interest is application of an electronic nose for food safety.

Muhammad Danu Adhityamurti is master's student of Department of Agricultural and Biosystems Engineering, Faculty of Agricultural Technology, Universitas Gadjah Mada, Indonesia, Indonesia. Currently, he is a member of the research group of agricultural control \& robotics. His research interest is application of an electronic nose for food quality process control.

Joko Purwo Leksono Yuroto Putro is bachelor's student of Department of Agricultural and Biosystems Engineering, Faculty of Agricultural Technology, Universitas Gadjah Mada, Indonesia, Indonesia. Currently, he is a member of the research group of agricultural control \& robotics. His research interest is application of an electronic nose for food quality assessment. 